\title{
Etiology of Amputation among Patients Presented At Helping Hand Institute of Rehabilitation Sciences Mansehra
}

\section{Keramat Ullah Keramat ${ }^{1}$, Mohammad Shazad Shahzad ${ }^{2}$, Jamal Tariq ${ }^{3}$, Abdul Haseeb Bhutta ${ }^{4}$}

1 Associate Professor, Helping Hand Institute of Rehabilitation Sciences Mansehra.

2, 4 Lecturer, Helping Hand Institute of Rehabilitation Sciences Mansehra.

3 Physiotherapist, Helping Hand Institute of Rehabilitation Sciences Mansehra.

Author's Contribution

1,4 Conception and design, Collection and assembly of data, ${ }^{2-3}$ Analysis and interpretation of the data, ${ }^{1-2}$ Critical revision of the article for important intellectual content, Statistical expertise ${ }^{1}$ Final approval and guarantor of the article.

Article Info.

Received: Sep 18, 2019

Acceptance: June 7, 2021

Conflict of Interest: None

Funding Sources: None

Address of Correspondence

Dr Keramat Ullah Keramat

Email Id: karamatjee@yahoo.com

Cite this article as: Keramat KU, Shahzad MS, Tariq J, Bhutta AH. Etiology of Amputation among Patients Presented At Helping Hand Institute of Rehabilitation Sciences Mansehra. JRCRS. 2021; 9(1). 18-21. DOI:

https://dx.doi.org/10.53389/JRCRS.20 $\underline{21090104}$

\section{A B S T R A C T}

Objective: The current study computes the amputation distribution and causes of amputation at only service of prosthetic and orthotics of Helping Hand Institute of Rehabilitation Sciences since the earthquake 2005.

Methodology: This retrospective study was conducted in the prosthetics and orthotics department of Helping Hand Institute of Rehabilitation Sciences Mansehra. The record of Helping Hand Institute of Rehabilitation Sciences over 12 years (July 2006 to July 2018) was evaluated and data on amputees were segregated. All patient's files who availed prosthetics and orthotics were reviewed thoroughly and incomplete record were excluded. The collected data were classified into 4 groups about age. Frequencies and descriptive statistics were applied to the collected data and analyzed by SPSS 21.

Results: A total of 564 cases met the inclusion criteria. The majority (79.6\%) patients were males as opposed to $20.4 \%$ females. And $66.1 \%$ were in the age group $20-60$ years. Unilateral cases were the communist (96.4\%) and mostly the right side (52.3\%). Traumatic cases were the highest at $74 \%$ among the amputations. Road Traffic Accidents were the leading causes of traumatic amputations, which accounted for $33 \%$ of amputations. The non-traumatic cases were $26 \%$ and diabetes (47.3) was the major cause followed by peripheral vascular disorders (16.2\%).

Conclusion: Traumatic causes of amputation were reported more than non-traumatic causes in 12 years of data. Males are more vulnerable than females. The high incidence of amputation due to road traffic accidents raises the question of road safety regulations. Diabetes is the leading cause of non-traumatic amputations.

Keywords: Amputation, Diabetes, Etiology, Trauma.

\section{Introduction}

On October 8, 2005, a massive earth quack of 7.6 on Richter scale struck Hazera division of Khyber Pukhtoon khwa (KPK) Pakistan that claimed 87350 lives, injured 128000 people, and leaving500000 people homeless. ${ }^{1}$ Various international relief agencies such as International Red Cross and Helping hand for relief and development intervened to deal with the aftermath of the disaster. After the acute relief activities were over, Helping Hand for Relief and Development established rehabilitation services in Mansehra city in 2006 to play a role in the rehabilitation of the disabled population resulted from the earthquake. From 2014 onward, services are being provided in a purpose build infrastructure. The services offered are physiotherapy, occupational therapy, orthotic/Prosthetics services, Speech and Language pathology and audiology. Accurate documentation procedure is being followed and so far more than 35,000 people of various rehabilitation needs have availed the services. ${ }^{2}$ Many injuries lead to the 
amputation of the limb after the earthquake. Exact number of amputees could not be determined.

Amputation is defined as "the removal of a limb or part of a limb by a surgical procedure to save the life of a person" and has been recognized as the oldest surgical procedure. $^{3}$ Multiple traumatic and non-traumatic etiological factors often lead to amputation. Dysvascular factors are common in the developed world in the elderly population. 4 The increased prevalence is dominant among the aging population due to dysvascular conditions in the developed world 5 and around 1.6 million people in the USA are an amputee and one in hundred and ninety (190) are currently living without a limb. It is anticipated that this number will be doubled by $2050 .{ }^{5}$

The amputation of the limb is a major event that causes significant physical and vocational consequences. ${ }^{6,7}$ In addition, amputees faces psychological issues such as anxiety, stress, low selfrespect, uselessness and loss of emotions which leads to their social isolation ${ }^{8}$. Feeling of hopelessness, constant sad mood, disturbance of sleep, and decrease functional abilities are the salient features of depression and dominate in an amputee's life 3, 9. Like any disability, social and environmental factors and the lack of the availability of services such as transportation, availability of a quality prosthesis and social support make the psychological status of an amputee worse. ${ }^{10,11}$ However, rehabilitation facilities for amputees are improving day by day in developed countries and for selected segment of the population in Pakistan, which are resulting in good functional outcomes and community integration. ${ }^{3}$ However, statistics in relation to the amputees are lacking especially in earthquake effected region of Hazera division.

The frequency and prevalence of amputation vary from place to place and country. The most common causes are trauma, complications of diabetes and peripheral vascular disease (PVD). The leading causes of amputation in developed countries are peripheral vascular diseases while infections, trauma, malignancies and uncontrolled diabetes are leading causes in developing countries. ${ }^{12-15}$

The major cause of amputation in Pakistan is trauma, unlike the developed countries. Road Traffic
Accidents (RTA) due to poor compliance with the regulation of traffic is reported to the major factor of amputation among traumatic causes in Pakistan ${ }^{15-17}$ with male more effected than females ${ }^{12,14,15}$ and burn contracture in children. ${ }^{18}$ Other causes include PVDs, congenital issues and a retrospective study conducted in India found trauma as a leading cause of amputation which accounts for about $70.3 \%$ in age below 60 s while $3.6 \%$ in over 60 years of age. Moreover, they concluded that peripheral vascular disease is the second most common type among amputees. ${ }^{19}$

The climate, culture, and terrain of Hazara division are different from the rest of the country and the world. Demographics of amputation are likely to be different as well. It is affected by natural calamities such as earth quack, floods, lightning, and landslides frequently. Therefore, the aim of this study was reporting the major etiology and frequency of amputation in patients presented at HHIRS Mansehra.

\section{Methodology}

A retrospective study was conducted in Helping Hand Institute of Rehabilitation Sciences Mansehra, Pakistan. The study was conducted between February 2018 and May 2018. Data were collected from prosthetics and orthotics department of the last 12 years (from July 2006 to July 2018). Ethical approval was taken from the research and ethics committee of HHIRS. The secondary data on amputation were collected from HHIRS clinical record and thoroughly reviewed. Patients of both genders who attended between 2006 and July 2018 were included. The exclusion criteria were patients' incomplete charts (files) and patients who attended after 2018. The data collected on all patients were classified into 4 age groups. Frequencies and descriptive statistics were calculated on the data gathered and the required result was computed. Data was analyzed by SPSS 21.

\section{Results}

A total of Twenty-nine thousand (29000) patient's charts were screened in which 602 amputee's charts were identified. Thirty-eight (38) charts were excluded since they were not complete and the remaining 564 patients were analyzed. The frequency of male amputees was dominating $79.6 \% \quad(n=449)$. Ages of the patients ranged from below 20 to above 60 years among 
which 18.6\% $(n=105)$ patients were between the age group of $0-20$ years, $38.1 \%(n=215)$ were of the age range of $21-40$ years, $33 \%(n=186)$ of the age group $41-$ 60 years, whereas the remaining $10.3 \%(n=58)$ patients were above the age 60 years. Among all the cases right side amputation was $52.3(n=295)$, left side was $44.1 \%$ $(n=249)$ and in $3.5 \%(n=20)$ were bilateral amputations. These statistics are shown in table $\mathrm{l}$.

\begin{tabular}{cccc}
\hline \multicolumn{3}{c}{ Table I: Demographic Details of Amputees } & \\
\hline & Groups & $\mathbf{n}(\%)$ & Total (N) \\
\hline Age Groups & $0-20$ & $105(18.6 \%)$ & 564 \\
\cline { 2 - 3 } & $21-40$ & $215(38.1 \%)$ & \\
\cline { 2 - 3 } & $41-60$ & $186(33.0 \%)$ & \\
\cline { 2 - 3 } & Above 60 & $58(10.3 \%)$ & \\
\hline Gender & Male & $449(79.6 \%)$ & \multirow{2}{*}{564} \\
\cline { 2 - 3 } & Female & $115(20.4 \%)$ & \\
\hline Side of & Unilateral & $544(96.4 \%)$ & 564 \\
\cline { 2 - 3 } amputation & Bilateral & $20(3.6 \%)$ & \\
\hline
\end{tabular}

Causes of amputations were identified and the frequency calculated. Trauma was the leading cause of amputation accounted for $73 \%$ of cases. Among the total traumatic cases $(n=416)$, RTA was the leading cause accounting for $33.1 \% \quad(n=138)$, and the second were earthquake victims $28.12 \%(n=117)$ as shown in table II. Other causes were fall $17 \%(n=71)$ and mechanical trauma of $9.8 \%$.

Among the non-traumatic causes of amputation (27\%), the most common indication for limb amputation was diabetes $47.3 \%(n=70)$, followed by vascular diseases $16.2 \%(n=24)$, infectious disease $6.8 \%(n=10)$, congenital causes $15.5 \%(n=23)$ and tumor $14.2 \%(n=21)$. The mentioned statistics are summarized in table 2 given below.

\begin{tabular}{lc}
\hline $\begin{array}{l}\text { Table II: Frequency and percentages of } \mathbf{4 1 6} \text { cases of } \\
\text { traumatic causes of amputation }\end{array}$ \\
\hline Conditions & Frequency (Percentage) \\
\hline RTA & $138(33.2 \%)$ \\
\hline Earthquake & $117(28.1 \%)$ \\
\hline Mechanical Trauma & $42(10.1 \%)$ \\
\hline Falls & $71(17.1 \%)$ \\
\hline Bomb Blast & $27(6.5 \%)$ \\
\hline Gun Shot & $21(5.0 \%)$ \\
\hline
\end{tabular}

\begin{tabular}{lc}
\hline \multicolumn{2}{l}{ Table III: Non-traumatic causes of amputation } \\
\hline condition & Frequency (Percentage) \\
\hline Diabetes & $70(47.3 \%)$ \\
\hline PVD & $24(16.2 \%)$ \\
\hline Infectious Disease & $23(6.8 \%)$ \\
\hline Congenital & $10(1.5 \%)$ \\
\hline
\end{tabular}

\begin{tabular}{ll}
\hline Tumor $21(14.2 \%)$ \\
\hline
\end{tabular}

\section{Discussion}

This study aimed to determine the demographics and etiology of amputation in Hazara division of Pakistan. The findings of this study suggest that the major causes of amputation in this region are traumatic in which the RTAs dominate like the findings in the developed countries and the urban hospital for the age groups selected in this study. The region was struck by the earth quack and major frequency of the amputee patients $(28.1 \%)$ still dominates the statistics. The bomb blast amputation $(6.5 \%)$ in the Hazara division were mainly due to mining of the Granite and not due to terrorism like the amputation of $21.6 \%$ at Peshawar. ${ }^{20}$ Earthquake victims rank $2^{\text {nd }}$ in the frequency ${ }^{15}$, unlike the other region of Pakistan.

Male amputees are significantly greater than females and these findings are consistent with the other region of Pakistan ${ }^{15}$ i.e. males are affected more $(79.6 \%)$ than females $(20.4 \%)$. The higher number of male amputees is because there are less female drivers and less mining workers since male dominates the laborer force of the region. A USA based study and other study reported the high prevalence of amputation in males than females $(28 \%))^{11,12}$

Indian study also reported the road traffic accident as the most common cause of amputation and the findings our study is consistent that we report $33 \%$ of cases due to $\mathrm{RTAs}^{17}$. A three-year prospective survey at the Armed Forces Institute of Rehabilitation Medicine (AFIRM), Pakistan found that Land mine blast was the leading cause $(59.3 \%)$ of amputation. ${ }^{18}$

Moreover, this study highlights diabetes as the most common indication (40.5\%) for limb amputation among the non-traumatic causes of amputation followed by vascular diseases (16.2\%). Diabetes is very common and the onset is quite early in Pakistan, therefore it is not surprising to see diabetes related amputation in the age groups of this study. ${ }^{21}$ In a case series previously conducted revealed complications of diabetes, followed by trauma was the leading indication of amputation. ${ }^{18}$

Forty-nine percent of amputations in Finland resulted from diabetic complication ${ }^{19}$. A similar pattern 
was also seen in another study conducted where diabetes with peripheral vascular disease and neuropathy were the main causes of amputations which also correlates with the current study and studies of Trautner and Dangelse. ${ }^{20}$, 21,22 Likewise in a retrospective study amputation in $63.6 \%$ of the patients was due to diabetic foot disease followed by trauma in $20.5 \%$ of cases. ${ }^{21}$

This study may not represent the full spectrum of amputation of the region since services are availed elsewhere as well. There were a lot of non-government organization who worked in the region for a limited time soon after the earthquake. The HHIRS initially 2006-2008) provided free of cost prothesis. The cost of prothesis is high for the local population and there are organization who provides free of cost prothesis and may have attracted a lot of the amputees at the time and later.

\section{Conclusion}

This study concludes that RTAs and earthquake were the leading traumatic causes of amputation. Diabetes was the leading cause among non-traumatic amputations.

\section{References}

1. Reliefweb. The Kashmir earthquake of October 8, 2005: Impacts in Pakistan. 26the Feb, 2006.

2. Comprehensive Rehabilation Services of helping hand Institute of Rehabiliation Sciences. 2018.

3. Rathore FA, Ayaz SB, Mansoor SN, Qureshi AR, Fahim M. Demographics of lower limb amputations in the Pakistan military: a single center, three-year prospective survey. Cureus. 2016; 8.

4. Barr S, Howe TE. Prosthetic rehabilitation for older dysvascular people following a unilateral transfemoral amputation. Cochrane Database of Systematic Reviews. 2018.

5. Ziegler-Graham K, MacKenzie EJ, Ephraim PL, Travison TG, Brookmeyer R. Estimating the prevalence of limb loss in the United States: 2005 to 2050. Arch Phys Med Rehabil. 2008; 89:422-9.

6. Ghous M, Gul S, Siddiqi FA, Pervaiz S, Bano S. DEPRESSION. The Professional Medical Journal. 2015; 22:263-6.

7. Bragaru M, Dekker R, Geertzen JH, Dijkstra PU. Amputees and sports. Sports medicine. 2011; 41:721-40.
8. Bhuvaneswar CG, Epstein LA, Stern TA. Reactions to amputation: recognition and treatment. Primary care companion to the Journal of clinical psychiatry. 2007; 9:303.

9. Singh $R$, Hunter J, Philip A. The rapid resolution of depression and anxiety symptoms after lower limb amputation. Clinical rehabilitation. 2007; 21:754-9.

10. Kashani J, Frank R, Kashani S, Wonderlich S, Reid J. Depression among amputees. The Journal of clinical psychiatry. 1983; 44:256-8.

11. McFarland LV, Choppa AJ, Betz K, Pruden JD, Reiber GE. Resources for wounded warriors with major traumatic limb loss. Journal of Rehabilitation Research \& Development. 2010; 47.

12. Kumar GK, Souza CD, Diaz EA. Incidence and causes of lower-limb amputations in a tertiary care center: Evaluation of the medical records in a period of 2 years. International Journal of Surgery. 2018; 2:16-9.

13. Abou-Zamzam Jr AM, Teruya TH, Killeen JD, Ballard JL. Major lower extremity amputation in an academic vascular center. Annals of vascular surgery. 2003; 17:86-90.

14. Ubayawansa D, Abeysekera W, Kumara M. Major lower limb amputations: experience of a tertiary care hospital in Sri Lanka. Journal of the College of Physicians and Surgeons Pakistan. 2016; 26:620-2.

15. Soomro N, Bibi R, Ahmed SI, Kamran B, Minhas MA, Siddiqui KY. EPIDEMIOLOGY OF AMPUTATION. The Professional Medical Journal. 2013; 20:261-5.

16. Shahzad A, Malik LA, Hussain H, Soomro SK. causes of amputation in pakistani population. International Journal of Rehabilitation Sciences (IJRS). 2016; 5:54-7.

17. Hassan Al Imam M, Alamgir $\mathrm{H}$, Jahan Akhtar $\mathrm{N}$, Hossain $Z$, Islam R, Sohrab Hossain M. Characterisation of persons with lower limb amputation who attended a tertiary rehabilitation centre in Bangladesh. Disabil Rehabil. 2020; 42:1995-2001.

18. Paudel B, Shrestha B, Banskota A. Two faces of major lower limb amputations. Kathmandu University medical journal (KUMJ). 2005; 3:212-6.

19. Pooja GD, Sangeeta L. Prevalence and aetiology of amputation in Kolkata, India: A retrospective analysis. Hong Kong Physiotherapy Journal. 2013; 31:36-40.

20. Ahmad A, Ashfaq O, Akhtar N, Rana T, Gul M. Causes of lower limb amputation in patients registered at pakistan institute of prosthetic and orthotic sciences peshawarpakistan. khyber medical university journal. 2019; 11:41-4.

21. Bahadar H, Mostafalou S, Abdollahi M. Growing burden of diabetes in Pakistan and the possible role of arsenic and pesticides. Journal of Diabetes \& Metabolic Disorders. 2014; 13:117. 